\title{
Optimum Power of Low-Temperature Plasma Selec tivity for Human Melanoma Cell Treatment
}

\author{
Sarut Chaisrisawadisuk, ${ }^{\mathrm{a},{ }^{\star}}$ Dheerawan Boonyawan, ${ }^{\mathrm{b}} \&$ Apirag Chuangsuwanit ${ }^{\mathrm{a}}$ \\ aDivision of Plastic Surgery, Department of Surgery, Faculty of Medicine, Siriraj Hospital, \\ Mahidol University, Bangkok, Thailand; 'Department of Physics and Materials Science, Faculty \\ of Science, Chiang Mai University, Chiang Mai, Thailand \\ *Address all correspondence to: Sarut Chaisrisawadisuk, M.D., FRCST, Division of Plastic Surgery, Department of Surgery, \\ Faculty of Medicine, Siriraj Hospital, Mahidol University, Bangkok, Thailand 10700, E-mail: sarut.cha@mahidol.ac.th
}

\begin{abstract}
The number of new cases of melanoma is increasing every year. Due to its specificity of treatment, plasma medicine has been claimed to be a novel adjunctive procedure. We evaluated the effects of a direct low-temperature plasma (LTP) device for selective tumor eradication, comparing between melanoma and normal keratinocyte cell lines. Human melanoma (G-361) and normal keratinocyte $(\mathrm{HaCaT})$ cell lines were subjected to LTP treatment. Different power levels and exposure durations of LTP were compared in both groups. After the treatment, a MTT assay was used to determine cell viability. The physical plasma characteristics of the three powers were also evaluated. It was found that low power (intensity 1 with frequency $10 \mathrm{~Hz}$ ) was 0.25 watts, while medium power (intensity 5 with frequency $50 \mathrm{~Hz}$ ) and high power (intensity 10, with frequency $100 \mathrm{~Hz}$ ) were 0.94 and 3.0 watts, respectively. Higher powers and longer durations of LTP treatment increased the incidence of cell death in both the HaCaT and G-361 cell lines. LTP eliminated slightly more G-361 than HaCaT cells at 10 and 30 seconds of exposure. At 60 seconds or more, LTP showed a decrease of more than 50\% in both the HaCaT and G-361 survival. Medium LTP power with 10-second exposure demonstrated a statistically significant difference between $\mathrm{HaCaT}$ and G-361 viabilities (77.1\% and 66.3\%, respectively; $P=0.01)$. LTP treatment at medium power (intensity 5 with frequency $50 \mathrm{~Hz}$, equal to 0.94 watts) at 10 -second duration showed a specificity for cancer eradication.
\end{abstract}

KEY WORDS: plasma medicine, plasma jet, melanoma, selectivity

\section{INTRODUCTION}

Plasma medicine is at the boundary of plasma physics, chemistry, and biomedical sciences. Plasma is considered the fourth state of matter next to solids, liquids, and gases. ${ }^{1}$ Low-temperature plasma (LTP), a technology based on quasi-neutral ionized gases at low temperatures, has been used as a novel treatment for tumors. "Plasma oncology," the term describing the use of LTP for tumor therapy, is a new field of plasma medicine. ${ }^{3}$

Due to the complexity of cancer, several targeted cancer therapies have been developed to reduce recurrence and increase survival. Examples include chemotherapy, radiotherapy, and targeted drugs. ${ }^{2}$ LTP has a demonstrated effect on cancer cell apoptosis that does not induce cell necrosis or disruption. ${ }^{4}$ Moreover, LTP appears to be selective for cancer cells since it has been shown to be more effective in tumor cells 
than in normal, non-neoplastic cells. ${ }^{3,5,6} \mathrm{~A}$ co-culture approach using melanoma cells and normal keratinocytes has demonstrated that plasma treatment induces growth arrest and significant cell death, and that these effects are much more pronounced in tumor cells. ${ }^{7}$

LTP contains a variety of charged particles, reactive oxygen species (ROS), reactive nitrogen species (RNS), and ultraviolet radiation, to name a few components. It is known that both ROS and RNS can promote oxidative stress and trigger different signaling pathways in cells. ${ }^{8}$ ROS metabolism and oxidative stress-responsive gene deregulation have been detected. ${ }^{5,9}$ According to these findings, intracellular ROS may be the leading cause of cell apoptosis. ${ }^{9,10}$ Apoptotic cell fragments are engulfed and removed by phagocytosis. ${ }^{3}$

A helium plasma jet has been shown to induce apoptotic effects on various types of cancer cells. ${ }^{3}$ Therefore, we performed this study to evaluate the effects of a direct plasma device, which uses helium gas to generate the plasma, on selective tumor eradication, with a comparison between melanoma and normal keratinocyte cell lines.

\section{METHODS}

\section{A. Cell Culture}

The human immortalized keratinocyte cell line (HaCaT) was cultured in Dulbecco's Modified Eagle medium containing 10\% fetal calf serum, 1\% penicillin/streptomycin, and 1\% L-glutamine. The human malignant melanoma cell line (G-361) was cultured in ATCC-formulated McCoy's 5a Medium Modified cell culture medium, supplemented with 10\% fetal bovine serum (Sigma-Aldrich, St. Louis, Missouri) and Pen/Strep (100 units/mL penicillin and $100 \mu \mathrm{g} / \mathrm{mL}$ streptomycin). All cells were obtained from the Mahidol University Cell Bank; they were incubated at $37^{\circ} \mathrm{C}$ in an atmosphere of $5 \% \mathrm{CO}_{2}$.

\section{B. Low-Temperature Plasma Characteristics}

The low-temperature plasma system (BIOPlasma Jet, Photo Bio Care, Bangkok, Thailand) is shown in Fig. 1. The system consists of a helium gas source and a gas flow controller connected to the handpiece of the plasma jet. The handpiece was constructed with an inner floating dielectric barrier electrode and an outer dielectric barrier, with a nozzle that delivers an approximately $2-\mathrm{mm}$ plasma beam spot, which is over 1-cm long, from the nozzle's exit to the ambient atmosphere (Fig. 2). The handpiece is connected to a high-frequency unipolar electrical generator of $27-30 \mathrm{KHz}$ range with a peak-topeak voltage of around $6-7 \mathrm{kV}$. The system allows adjustable intensity from 1 to 10 by duty cycle modulation. It also allows a repetitive pulsing rate adjustment of $10-110 \mathrm{~Hz}$ (Fig. 1). The maximum power supply from the household AC socket is kept at 50 watts input, and the maximal power output is under 5 watts. Helium gas with a flow rate of $2 \mathrm{~L} / \mathrm{min}$ was utilized in this study to generate the low-temperature plasma jet. 


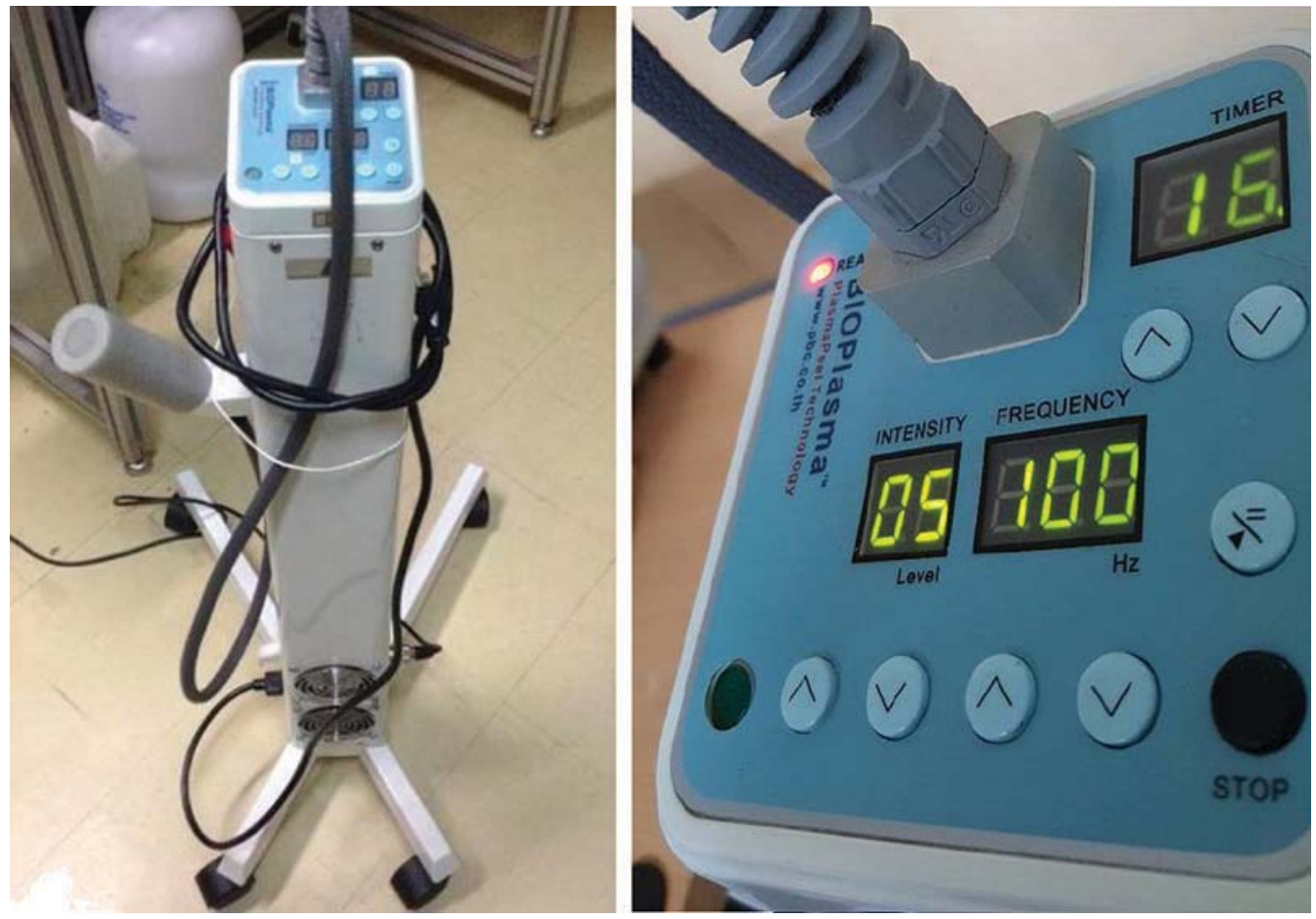

FIG. 1: LTP device

\section{Physical Plasma Parameter Analysis}

Evaluation of the plasma parameters was conducted by the Plasma and Beam Physics Research Facility (PBP) of Chiang Mai University. The Lissajous method was used

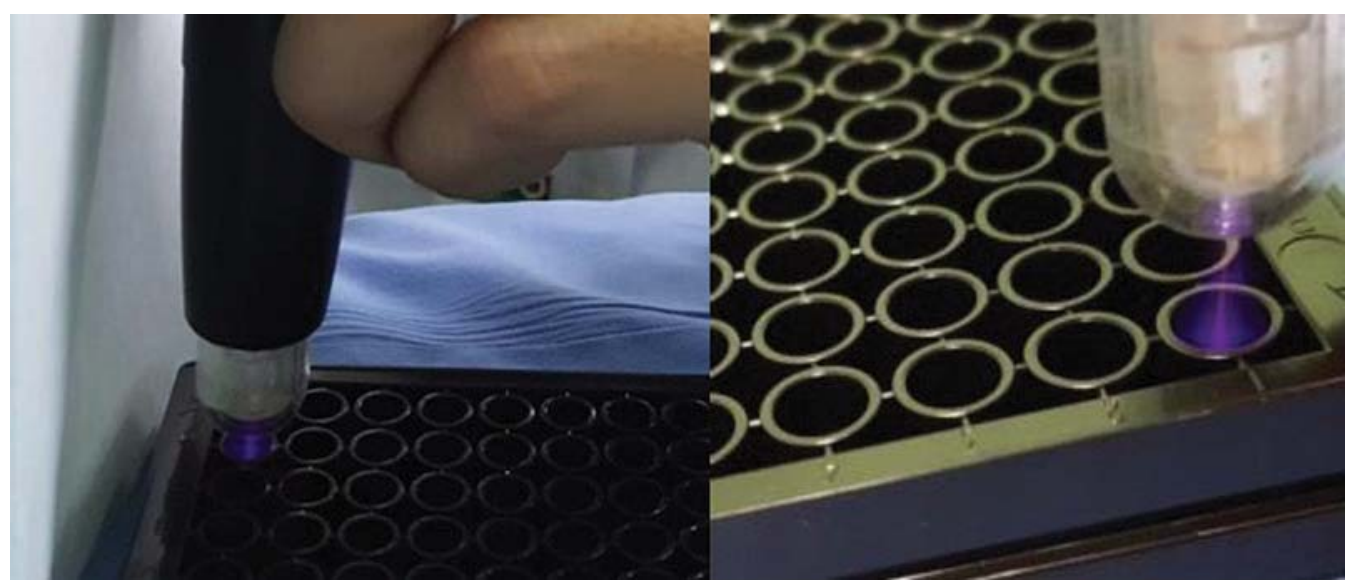

FIG. 2: Floating dielectric barrier electrode with 2-mm spot and 1-cm plasma beam length

Volume 9, Issue 1, 2019 
to analyze plasma power output at low (intensity 1 with frequency $10 \mathrm{~Hz}$ ), medium (intensity 5 with frequency $50 \mathrm{~Hz}$ ), and high (intensity 10 with frequency $100 \mathrm{~Hz}$ ) powers. A surface temperature evaluation was carried out using an infrared thermometer (Fig. 3). Temperatures before and after treatment were evaluated for exposure times ranging from 1 to $6 \mathrm{~min}$. The distance between the surface and the plasma tip was $1 \mathrm{~cm}$.

\section{Low-Temperature Plasma Treatment of Cell Cultures}

HaCaT and G-361 cells were subcultured at a density of 20,000 cells per well on two 96 -well plates in different rows. Media were added to the wells and cultured for $24 \mathrm{~h}$ before the LTP treatment. The media were subsequently removed, and all treatments were conducted at $25^{\circ} \mathrm{C}$ (room temperature). After LTP treatment, the media were replaced, and the cells cultured for an additional 24 hours.

The HaCaT and G-361 cells were treated under different LTP power conditions, including intensity and frequency (parameters that can alter LTP discharge power and affect cell behavior). After $24 \mathrm{~h}$ of culture, the attached cell numbers were compared with untreated controls. Duration of treatment was compared at 10, 30, 45, 60, and $100 \mathrm{~s}$ (Fig. 4). For each treatment, the distance between the LTP tip and the plate bottom was $1 \mathrm{~cm}$. Following treatment under the selected conditions, the HaCaT and G-361 cells were cultured for an additional 24 hours under standard cell culture conditions. Cell viabilities were subsequently assessed with MTT assays.

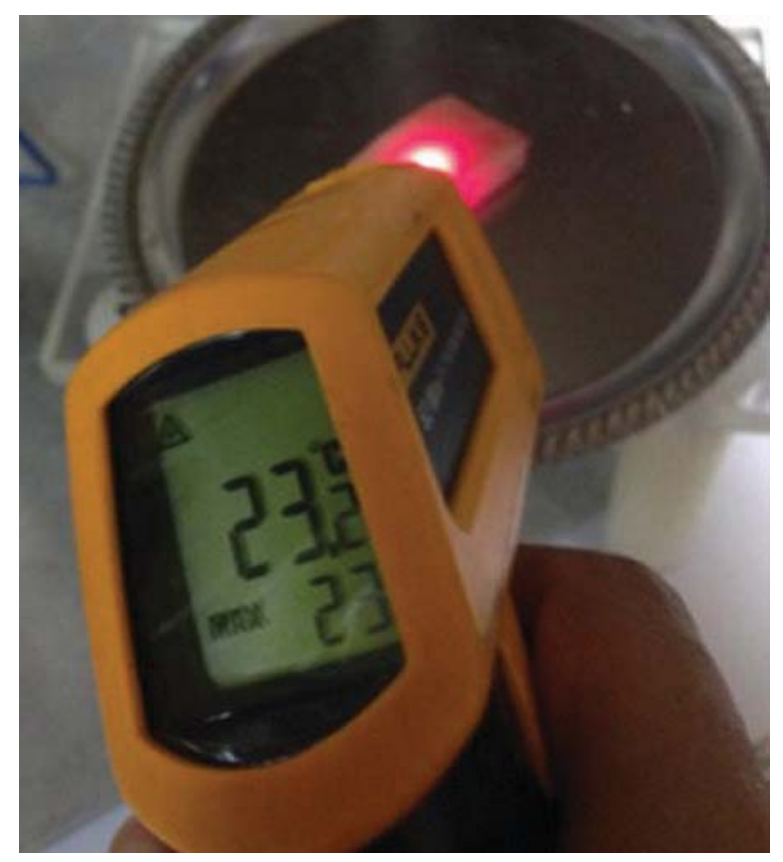

FIG. 3: Infrared thermometer for surface temperature evaluation 


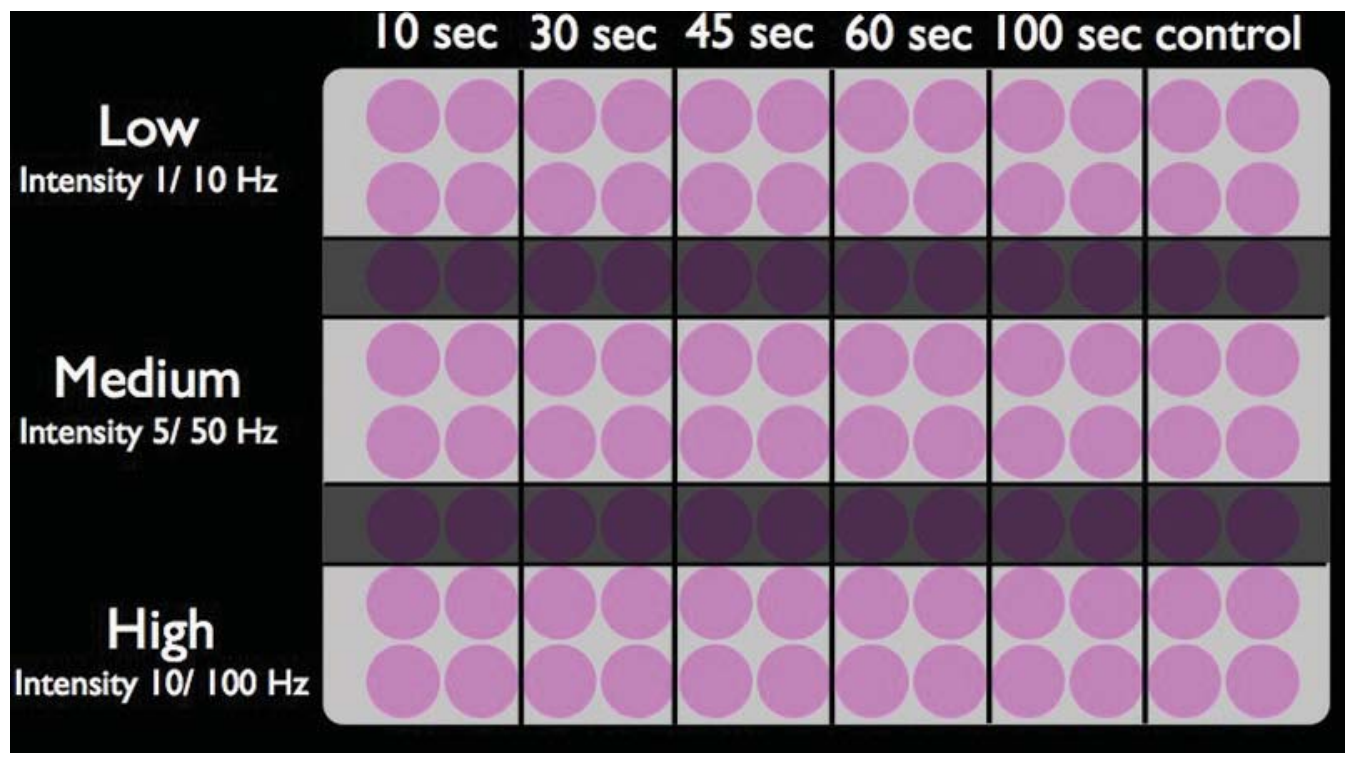

FIG. 4: Scheme showing various conditions and durations of LTP treatment for each 96-well plate

\section{E. MTTAssays}

Cell viabilities were tested with an MTT (3-[4,5-dimethylthiazol-2-yl]-2,5-diphenyltetrazolium bromide) tetrazolium reduction assay. Viable cells with active metabolism convert MTT into purple formazan with an absorbance maximum near $570 \mathrm{~nm}$. Dead cells lose the ability to convert MTT into formazan (Fig. 5).

In accordance with the manufacturer's instructions, the MTT assay (Sigma-Aldrich, St. Louis, Missouri) was performed on the plated cells $48 \mathrm{~h}$ after the low-temperature plasma application, and absorbance at $570 \mathrm{~nm}$ was measured. Mean percentage of viable cells after three experiments was used for data analysis.

\section{F. Statistical Analysis}

The experiments were repeated three times for each group. Data were presented as mean values \pm standard deviation (SD), and were analyzed with the student's $t$-test for pairwise comparisons. Statistical significance was set at $P<0.05$. The effects of power and timing were analyzed via two-way ANOVA. SPSS, v. 18 (IBM, Armonk, New York) was used for data analysis.

\section{RESULTS}

\section{A. Physical Plasma Parameters}

As to power output evaluation, low power (intensity 1 with frequency $10 \mathrm{~Hz}$ ) revealed a power output of 0.25 watts (Fig. 6). By comparison, medium power (intensity 5 with 


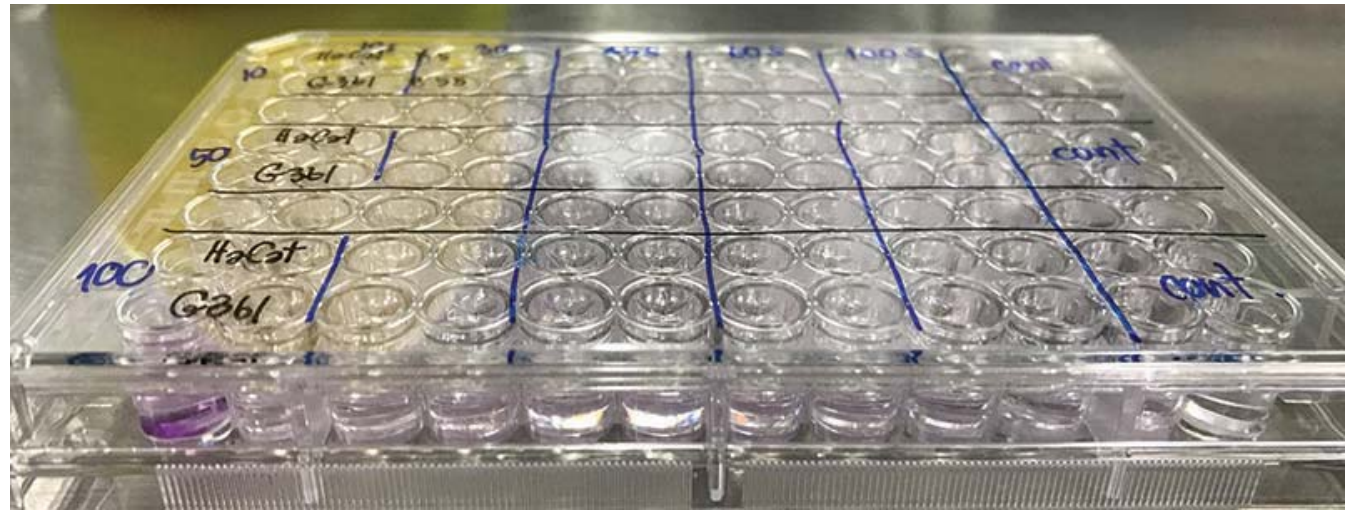

FIG. 5: MTT assay after LTP treatment, showing purple formazan before spectrophotometry

frequency $50 \mathrm{~Hz}$ ) and high power (intensity 10 with frequency $100 \mathrm{~Hz}$ ) had outputs of 0.94 and 3.0 watts, respectively (Figs. 7 and 8).

Surface temperature changes were evaluated for varying durations of plasma exposure. The temperature gradient was increased by $1^{\circ} \mathrm{C}$ once exposure reached $1 \mathrm{~min}$. After 2 min of treatment, the gradient was increased by $2^{\circ} \mathrm{C}$. Each gradient was raised by a further $3^{\circ} \mathrm{C}$ after 3,4 , and 5 min of treatment. Finally, following 6 min of treatment, the surface temperature was increased by $4^{\circ} \mathrm{C}$. The data are shown in Fig. 9.

\section{B. Low-Temperature Plasma Treatment in Cell Culture}

After conducting the experiment three times, cell viability percentages were calculated as means $\pm \mathrm{SD}$ (Table 1$)$.

At low power (0.25 watts), G-361 cell viabilities were $78.5 \%, 73.6 \%, 68.7 \%, 59.0 \%$, and $9.9 \%$ after $10,30,45,60$, and 100 s of exposure, respectively. In comparison, HaCaT

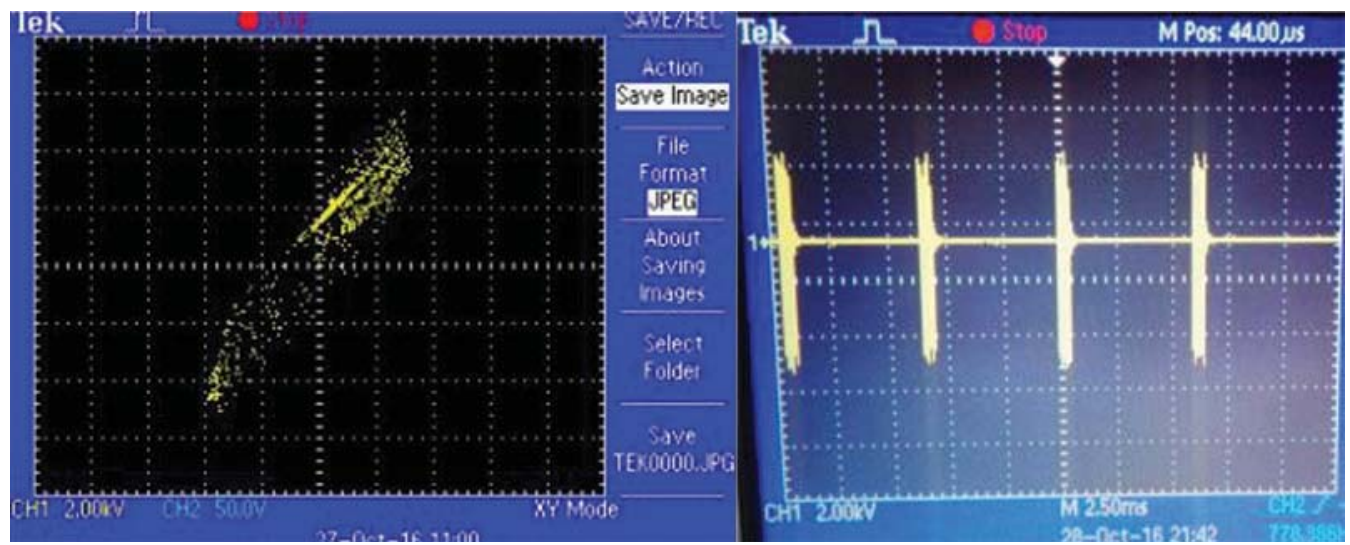

FIG. 6: Low plasma power output of 0.25 watts in the Lissajous method 


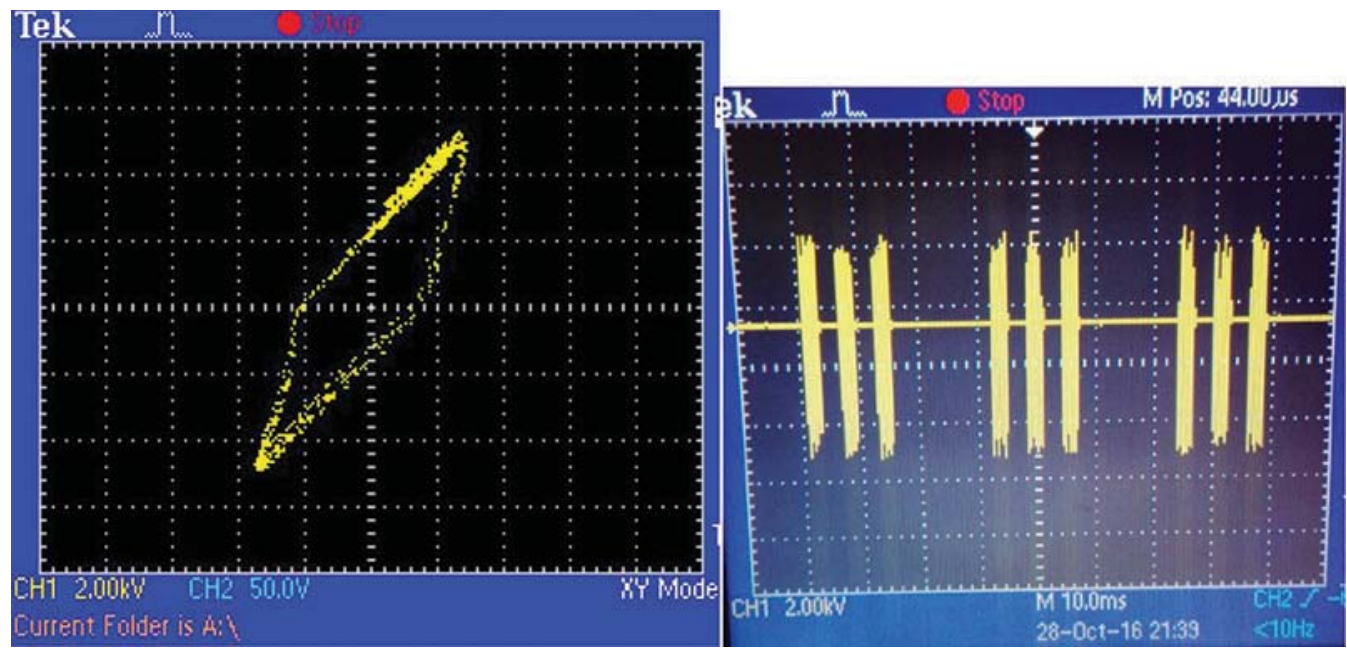

FIG. 7: Medium plasma power output of 0.94 watts in the Lissajous method

survivals were $81.8 \%, 72.4 \%, 66.3 \%, 51.2 \%$, and $7.6 \%$ after $10,30,45,60$, and $100 \mathrm{~s}$ of exposure, respectively.

As to medium power (0.94 watts), G-361 cell viabilities were $66.3 \%, 55.1 \%, 54.0 \%$, $50.6 \%$, and $7.9 \%$ after $10,30,45,60$, and $100 \mathrm{~s}$ of exposure, respectively. HaCaT survivals were $77.1 \%, 63.0 \%, 56.9 \%, 52.8 \%$, and $7.0 \%$ after $10,30,45,60$, and $100 \mathrm{~s}$ of exposure, respectively.

In the case of high power (3.0 watts), G-361 cell viabilities were $70.6 \%, 64.3 \%$, $55.4 \%, 42.1 \%$, and $7.6 \%$ after $10,30,45,60$, and $100 \mathrm{~s}$ of exposure, respectively. HaCaT survivals were $77.2 \%, 64.5 \%, 53.2 \%, 32.7 \%$, and $7.6 \%$ after $10,30,45,60$, and $100 \mathrm{~s}$ of exposure, respectively.

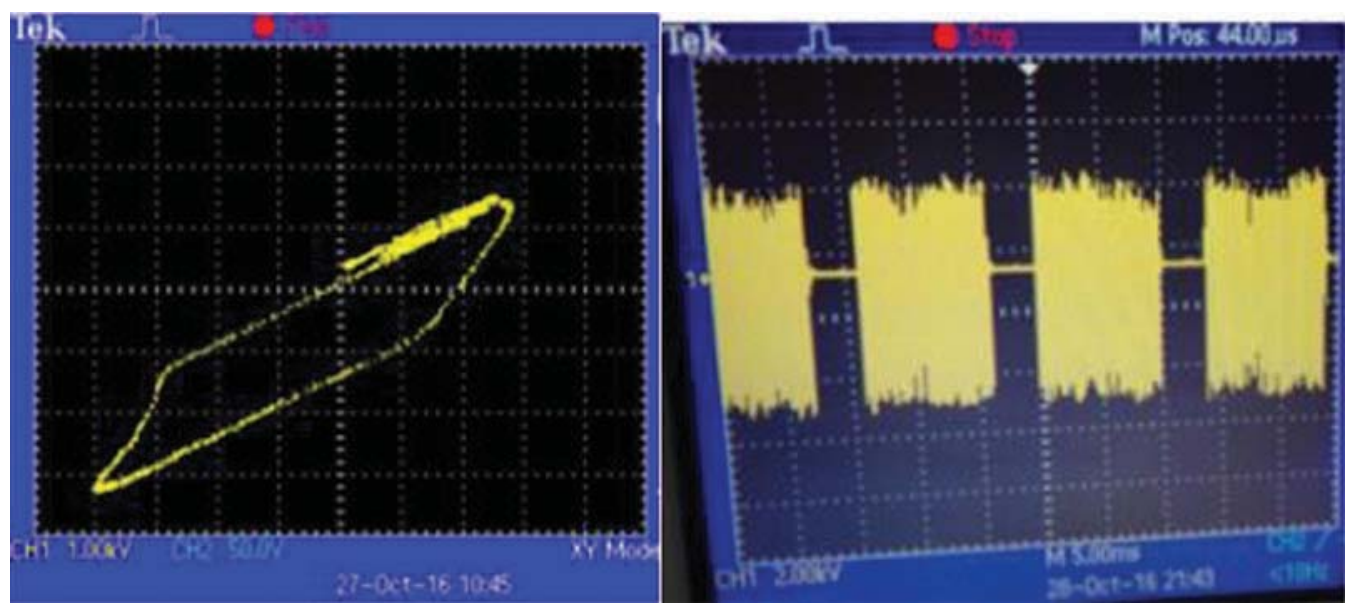

FIG. 8: High plasma power output of 3.0 watts in the Lissajous method

Volume 9, Issue 1, 2019 


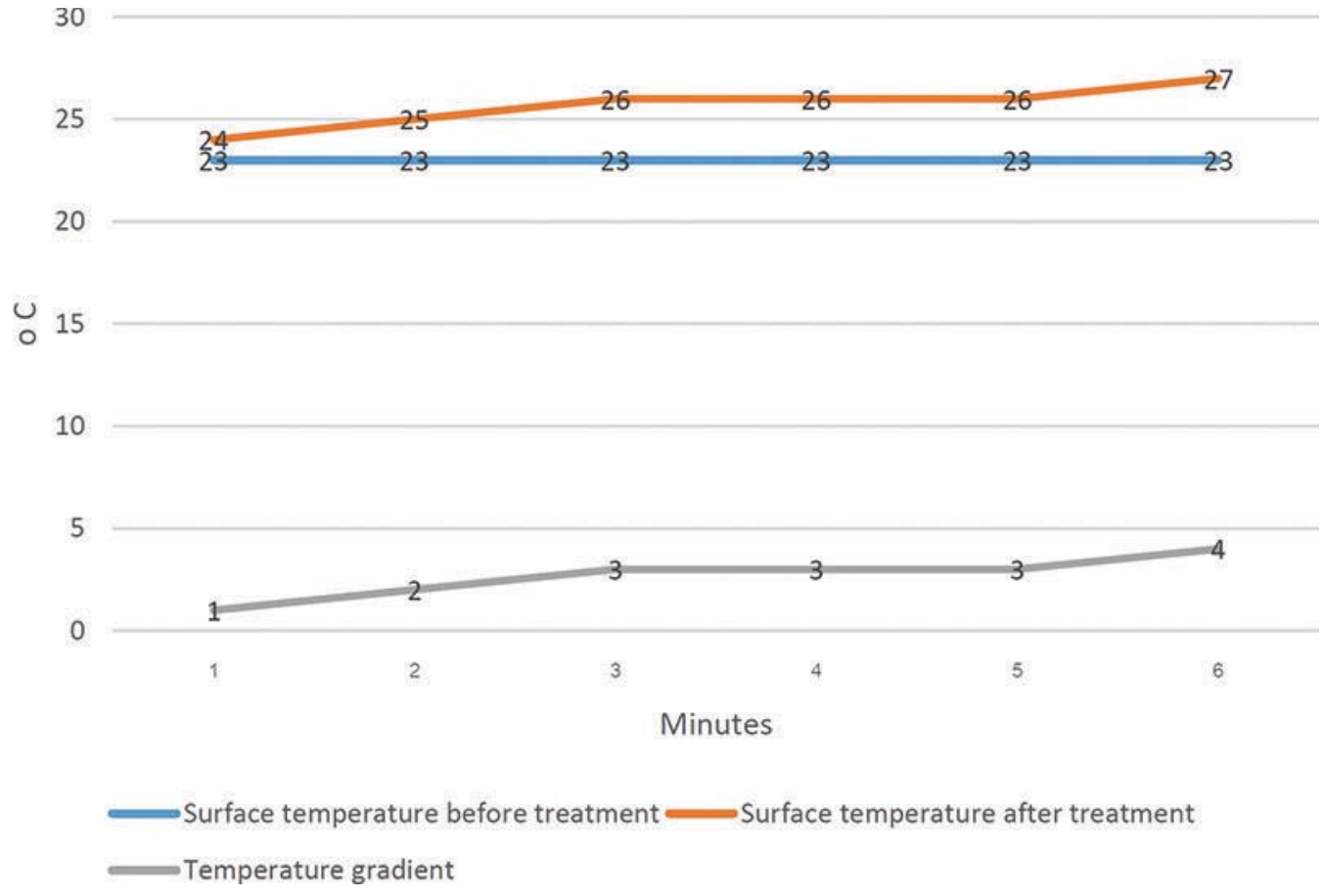

FIG. 9: Temperature gradients after plasma exposure

The data revealed that, for LTP treatment at medium power with $10 \mathrm{~s}$ of exposure, there was a statistically significant difference between $\mathrm{HaCaT}$ and G-361 viabilities (77.1\% and $66.3 \%$, respectively; $P=0.01)$. However, there were no statistical differences in cell viabilities for the other combinations of power level and exposure duration.

The effects of power level and exposure duration on $\mathrm{HaCaT}$ and G-361 cell viabilities were analyzed and are shown in Figs. 10 and 11, respectively. HaCaT cell viability

TABLE 1: Mean percentage \pm SD of viable cells after three rounds of LTP treatments

\begin{tabular}{|c|c|c|c|c|c|c|}
\hline $\begin{array}{c}\text { Power } \\
\text { (watts) } \\
\text { Time (s) }\end{array}$ & $\mathbf{0 . 2 5}$ & $\mathbf{0 . 9 4}$ & $\mathbf{3 . 0}$ & $\mathbf{0 . 2 5}$ & $\mathbf{0 . 9 4}$ & $\mathbf{3 . 0}$ \\
\hline Control & 100 & 100 & 100 & 100 & 100 & 100 \\
\hline 10 & $81.8 \pm 9.5$ & $77.1 \pm 3.1$ & $77.2 \pm 10.7$ & $78.5 \pm 14.6$ & $66.3 \pm 7.8$ & $70.6 \pm 6.9$ \\
\hline 0 & $72.4 \pm 7.2$ & $63.0 \pm 3.4$ & $64.5 \pm 4.1$ & $73.6 \pm 15.0$ & $55.1 \pm 9.5$ & $64.3 \pm 9.8$ \\
\hline 45 & $66.3 \pm 9.4$ & $56.9 \pm 2.9$ & $53.2 \pm 10.0$ & $68.7 \pm 15.5$ & $54.0 \pm 9.3$ & $55.4 \pm 16.9$ \\
\hline 60 & $51.2 \pm 20.4$ & $52.8 \pm 3.4$ & $32.7 \pm 19.5$ & $59.0 \pm 15.7$ & $50.6 \pm 9.1$ & $42.1 \pm 21.2$ \\
\hline 100 & $7.6 \pm 5.0$ & $7.0 \pm 4.6$ & $7.6 \pm 5.3$ & $9.9 \pm 4.1$ & $7.9 \pm 3.7$ & $7.6 \pm 3.2$ \\
\hline
\end{tabular}




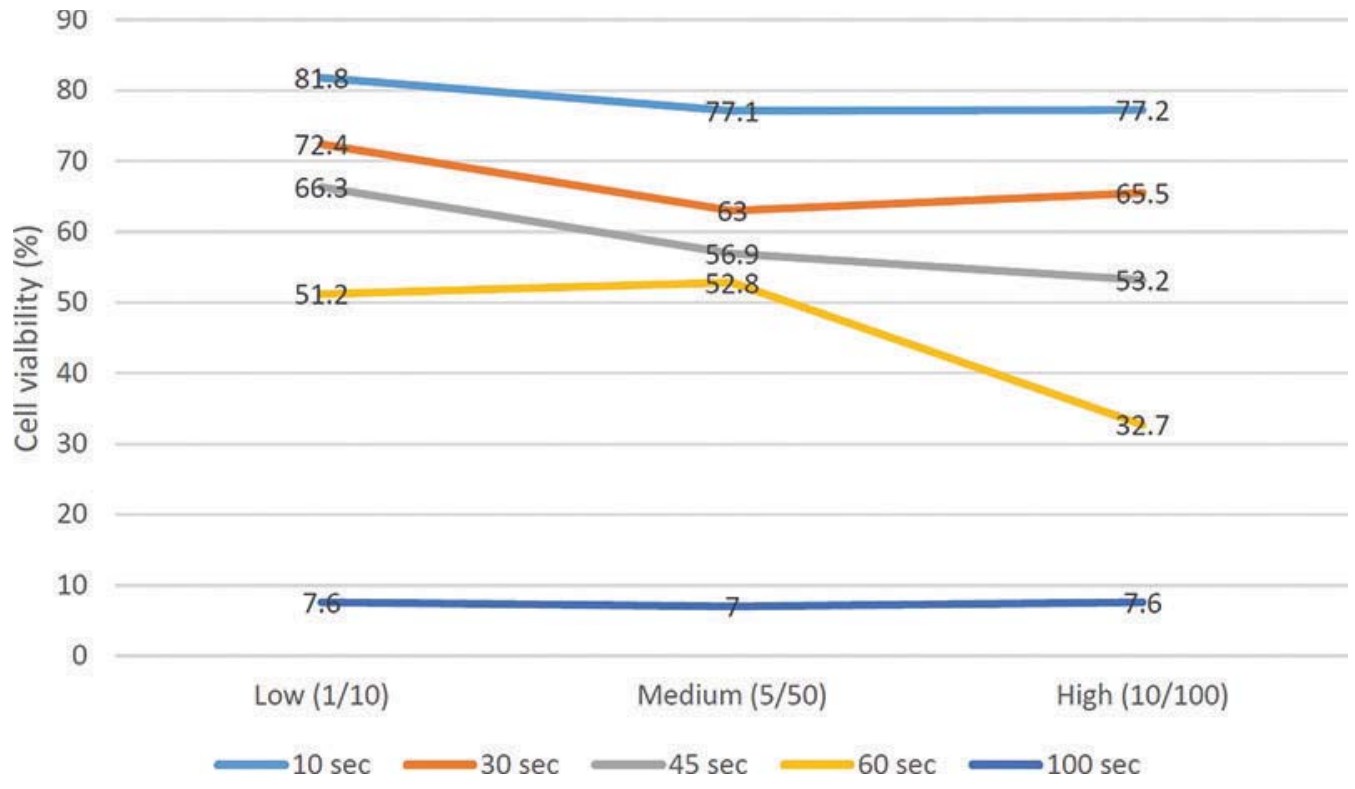

FIG. 10: Mean percentage of $\mathrm{HaCaT}$ cell viabilities after LTP treatment

decreased at higher power levels $(P=0.004)$ and longer exposures $(P=0.00)$. Similar results were found with G-361 cells in that viability decreased at higher power levels $(P=0.001)$ and longer exposures $(P=0.00)$.

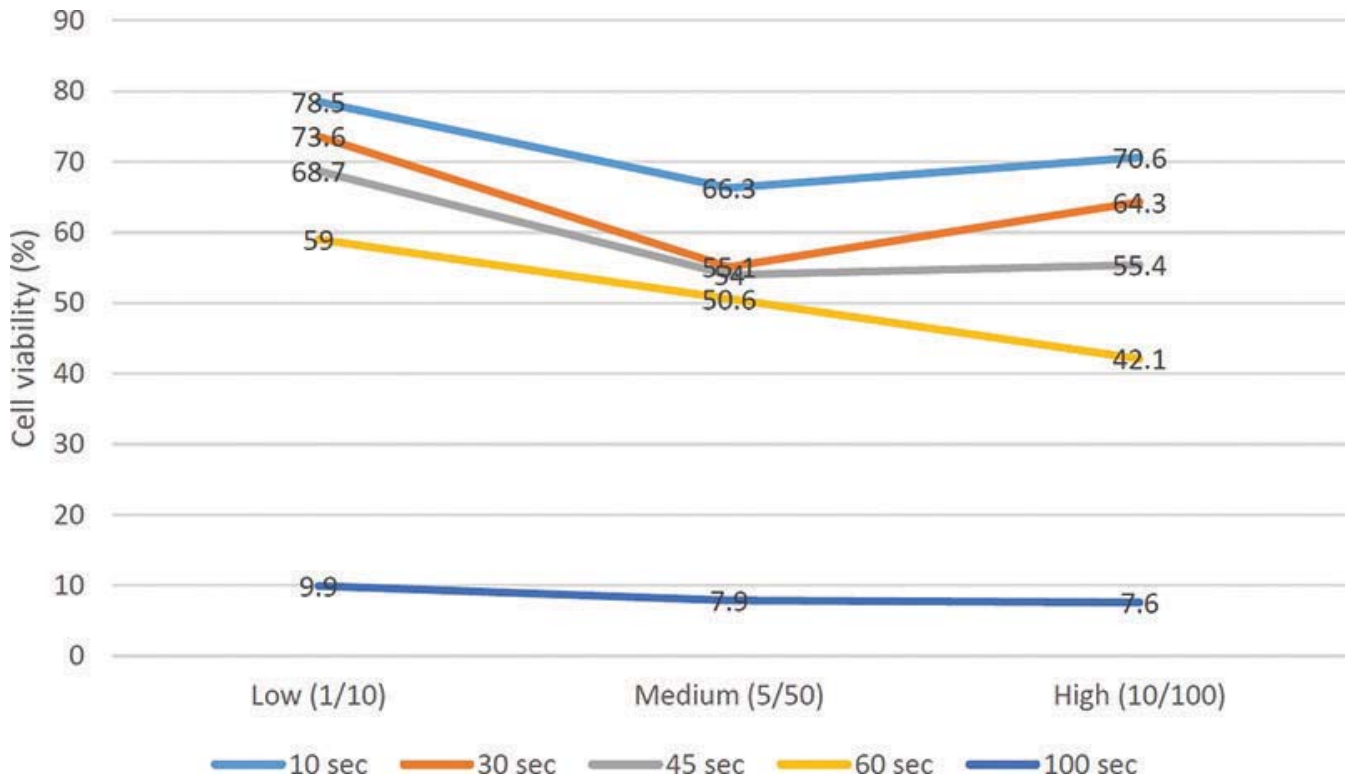

FIG. 11: Mean percentage of G-361 cell viabilities after LTP treatment

Volume 9, Issue 1, 2019 


\section{DISCUSSION}

Incidence of melanoma is increasing every year. ${ }^{11}$ Several modalities of treatment, such as surgery and radiation, are deployed in its eradication. However, even after complete tumor removal, recurrence and metastasis still occur. New treatment approaches are needed. ${ }^{12}$

The results of the present study show that higher power and longer duration of LTP treatment decrease cell viability in both $\mathrm{HaCaT}$ and G-361 cells. MTT assay results revealed that LTP eliminated slightly more G-361 cells than HaCaT cells at 10 and $30 \mathrm{~s}$ of exposure. At exposures of $60 \mathrm{~s}$ or more, LTP decreased both HaCaT and G-361 survivals by more than $50 \%$. Exposure at that duration may be improper for further cancer treatment.

Zucker et al. showed selectivity of a nonthermal plasma torch for melanoma cells over normal keratinocytes in a co-culture system. Their study used a primary cell culture for plasma treatment, which had a frequency of $112-117 \mathrm{kHz}$, a flow rate of 3-4.7 $\mathrm{L} / \mathrm{min}$, a minimal fluid level of $0.2 \mathrm{~mL}$ for media in the dish, and a treatment time of $10 \mathrm{~s}^{7}$

Here, medium LTP power (intensity 5 with frequency $50 \mathrm{~Hz}$ ) and $10 \mathrm{~s}$ of exposure significantly eradicated G-361 but not HaCaT cells - that is, 10\% more melanoma cells than keratinocytes. This finding differs from that of a previous study, in which LTP diminished cell viability after 30 and 45 s of treatment. ${ }^{6}$ A shorter time exposure would help to save helium gas and the time needed for each area of treatment. Based on the present study's findings, in order to selectively affect melanoma cells rather than normal keratinocytes, plasma treatment power should be under $10 \mathrm{~J}$.

ROS and RNS generated from LTP are believed to be the cause of cell death. Among plasma technology types, jet plasma has been widely used. In this study, we used dielectric barrier discharge technology, which generates a microfilamentous plasma jet and a steady current. This technology has been shown to cause cell blebbing by opening pores and disrupting cell membranes. ${ }^{7}$

\section{CONCLUSIONS}

This study showed the efficacy of LTP treatment for the melanoma cell line, for which medium power ( 0.94 watts) and 10-s duration showed specificity for cancer eradication. One of the limitations of this study was its in vitro status; an in vivo study should be organized.

\section{ACKNOWFDGMENTS}

The authors would like to thank Dr. Kitipong Soontrapa and Ms. Sunisa Duangsaard from the Department of Pharmacology, Faculty of Medicine, Siriraj Hospital, Mahidol University, for kind contributions in the cell culture laboratory. Photo Bio Care Co. Ltd., Bangkok, Thailand, provided the plasma jet equipment, including the plasma generator and plasma jet handpiece for conducting the experiment. The authors have no financial 
Optimum Power of Low-Temperature Plasma in Melanoma Selectivity

interest to declare in relation to the content of this article. The article processing charge was paid by the authors.

\section{REFERENCES}

1. Fridman G, Friedman G, Gutsol A, Shekhter AB, Vasilets VN, Fridman A. Applied plasma medicine. Plasma Process Polym. 2008;5(6):503-33.

2. Volotskova O, Hawley TS, Stepp MA, Keidar M. Targeting the cancer cell cycle by cold atmospheric plasma. Sci Rep. 2012;2:636.

3. Schlegel J, Köritzer J, Boxhammer V. Plasma in cancer treatment. Clin Plasma Med. 2013;1(2):2-7.

4. Keidar M. Plasma for cancer treatment. Plasma Sources Sci Technol. 2015;24(3):033001.

5. Keidar M, Walk R, Shashurin A, Srinivasan P, Sandler A, Dasgupta S, Ravi R, Guerrero-Preston R, Trink B. Cold plasma selectivity and the possibility of a paradigm shift in cancer therapy. Br J Cancer. 2011;105(9):1295-301.

6. Guerrero-Preston R, Ogawa T, Uemura M, Shumulinsky G, Valle BL, Pirini F, Ravi R, Sidransky D, Keidar M, Trink B. Cold atmospheric plasma treatment selectively targets head and neck squamous cell carcinoma cells. Int J Mol Med. 2014;34(4):941-6.

7. Zucker SN, Zirnheld J, Bagati A, DiSanto TM, Des Soye B, Wawrzyniak JA, Etemadi K, Nikiforov M, Berezney R. Preferential induction of apoptotic cell death in melanoma cells as compared with normal keratinocytes using a non-thermal plasma torch. Cancer Biol Ther. 2014;13(13):1299-306.

8. Kong MG, Kroesen G, Morfill G, Nosenko T, Shimizu T, van Dijk J, Zimmermann JL. Plasma medicine: an introductory review. New J Phys. 2009;11(11):115012.

9. Vandamme M, Robert E, Lerondel S, Sarron V, Ries D, Dozias S, Sobilo J, Gosset D, Kieda C, Legrain B, Pouvesle JM, Pape AL. ROS implication in a new antitumor strategy based on nonthermal plasma. Int J Cancer. 2012;130(9):2185-94.

10. Sensenig R, Kalghatgi S, Cerchar E, Fridman G, Shereshevsky A, Torabi B, Arjunan KP, Podolsky E, Fridman A, Friedman G, Azizkhan-Clifford J, Brooks AD. Non-thermal plasma induces apoptosis in melanoma cells via production of intracellular reactive oxygen species. Ann Biomed Eng. 2011;39(2):674-87.

11. Howlader N, Krapcho M, Miller D, Bishop K, Altekruse SF, Kosary CL, Yu M, Ruhl J, Tatalovich Z, Mariotto A, Lewis DR, Chen HS, Feuer EJ. SEER cancer statistics review, 1975-2013 Bethesda, MD.: National Cancer Institute; 2016. Available from: http://seer.cancer.gov/csr/1975_2013/.

12. Daeschlein G, Scholz S, Lutze S, Arnold A, von Podewils S, Kiefer T, Tueting T, Hardt O, Haase H, Grisk O, Langner S, Ritter C, von Woedtke T, Jünger M. Comparison between cold plasma, electrochemotherapy and combined therapy in a melanoma mouse model. Exp Dermatol. 2013;22(9):582-6.

Volume 9, Issue 1, 2019 
